\title{
Membrane and Subcellular Muscle Injury Are Induced by Single or Multiple Exposure to Cigarette Smoke
}

\author{
Ana Maria Fleig-Mayer', Alba Ramirez-Sarmiento ${ }^{2,3}$, Amanda Iglesias ${ }^{4,5}$, \\ Montserrat Morlá4,5, Carlos Coronell'2, Diego Rodríguez ${ }^{2,3}$, Simona Pichinni6, \\ Josep Lloreta $^{7,8}$, Piergiorgio Zuccaro ${ }^{6}$, Xavier Busquets ${ }^{4}$, Joaquim Gea ${ }^{3,4}$, \\ Jose R. Jardim 1 , Mauricio Orozco-Levi $2,3,4,7^{*}$ \\ ${ }^{1}$ Centro Universitário do Triângulo (UNITRI), Avenida nicomedes Alves Dos Santos, 4545-Gavea, Uberlândia; \\ Pulmonary Rehabilitation Center, Respiratory Division, Federal University of São Paulo, São Paulo, Brazil \\ ${ }^{2}$ Group of Research in Injury, Immune Response and Function (LIF), Municipal Institute of Medical Research \\ (IMIM), Carrer Dr. Aiguader 88, Barcelona, E-08003, Spain \\ ${ }^{3}$ Servei de Pneumologia, Hospital del Mar, Passeig Maritim 25, Barcelona, E-08003, Spain \\ ${ }^{4}$ Centro en Red de Investigación de Enfermedades Respiratorias (CIBERES), Recinto Hospital Joan March \\ Carretera Soller Km. 12, 07110, Bunyola, Mallorca, Illes Balears, Spain \\ ${ }^{5}$ Institut Universitari d'Investigació en Ciències de la Salut (IUNICS) and Department de Biologia, Universitat \\ Illes Balears (UIB); Cra de Valldemossa, Km 7.5, Palma, Illes Balears, Spain \\ ${ }^{6}$ Laboratorio Di Biochimica Clinica, Istituto Superiore Di Sanitá. Viale Regina Elena 299, 00161, Roma, Italy \\ ${ }^{7}$ Respiratory Department, Fundación Cardiovascular de Colombia, Calle 155A 23-58, Floridablanca, Santander, \\ Colombia \\ ${ }^{8}$ Servei d'Anatomia Patológica, Hospital del Mar, Passeig Maritim 25, Barcelona, E-08003, Spain \\ Email: *mauricioorozco@fcv.org
}

Received 11 March 2014; revised 11 April 2014; accepted 30 April 2014

Copyright (C) 2014 by authors and Scientific Research Publishing Inc.

This work is licensed under the Creative Commons Attribution International License (CC BY).

http://creativecommons.org/licenses/by/4.0/

(c) (i) Open Access

\section{Abstract}

Cigarette smoking is the main cause of chronic obstructive pulmonary disease (COPD). Diaphragm injury is observed in patients with COPD. However, the potential role of smoking in triggering or perpetuating muscle injury is unknown. The present study was aimed at evaluating the potential role of commercial tobacco smoke as a direct cause of skeletal muscle injury in experimental conditions. Seventy Wistar rats $(170-250 \mathrm{~g})$ were assigned to smoking $(\mathrm{n}=49)$ or non-smoking $(\mathrm{n}=$ 21) groups. The smoking groups were submitted to a single or multiple (i.e., five or thirty) daily sessions of cigarette smoking in an inhalatory chamber (time length: $\mathbf{2} \mathrm{h}$ each session). The level of exposure was constant and assessed by $C 0$ concentrations (50 ppm) and serum cotinine analy-

*Corresponding author.

How to cite this paper: Fleig-Mayer, A.M., et al. (2014) Membrane and Subcellular Muscle Injury Are Induced by Single or Multiple Exposure to Cigarette Smoke. Open Journal of Pathology, 4, 125-137.

http://dx.doi.org/10.4236/ojpathology.2014.43019 
sis. Animals submitted to a single smoke exposure and the corresponding controls were euthanized in groups at $0 \mathrm{~h}, 2 \mathrm{~h}, 4 \mathrm{~h}, 24 \mathrm{~h}$ or $48 \mathrm{~h}$ after completing the exposure. Animals submitted to multiple exposures were euthanized at $0 \mathrm{~h}$ after smoking. Samples from vastus lateralis muscle were obtained and processed for assessing cell injury and selected protein expression. Monoclonal anti-albumin antibodies were used to identify muscle fibers with sarcolemmal (membrane) injury. Subcellular muscle injury was assessed using transmission electron microscopy (EM). MyoD, myogenin and $\alpha$-tubulin were immunodetected using western blot techniques. Exposure to cigarette smoke associated with significant membrane damage (mean relative difference (MRD) with controls: $+181 \%, p=0.004$ ) and sarcomere disruptions (MRD: $+226 \%, p=0.001$ ). Expression of MyoD and myogenin (normalized to $\alpha$-tubulin) were significantly increased at $4 \mathrm{~h}$ and remained increased at $48 \mathrm{~h}$ post-exposure. We conclude that not only a single but also consecutive exposure to tobacco smoke have acute deleterious effects on peripheral muscle structure. A rapid induction of subrogate markers of skeletal muscle stress and repair processes associates to sarcolemmal and sarcomere damage.

\section{Keywords}

Skeletal Muscle, Muscle Injury, Muscle Regeneration, Quadriceps, Cigarette Smoking

\section{Introduction}

Chronic obstructive pulmonary disease (COPD), mainly induced by tobacco smoking, represents a major cause of disability and mortality in all countries, resulting in an important economic and social burden [1]. The main mechanisms that contribute to airflow limitation in COPD are fixed narrowing of small airways, emphysema and luminal obstruction with mucus secretions. COPD is characterized by a chronic inflammatory process in the pulmonary tissue associated with extra-pulmonary effects and is considered a complex, systemic disease [2].

Skeletal muscle dysfunction (i.e., decreased in strength or endurance) is one of the relevant extrapulmonary impairments frequently found in patients with COPD. This dysfunction is not merely a descriptive finding but has clinical relevance: muscle dysfunction relates to increased need for medical assistance and decreased survival of COPD patients [3]-[6]. In addition, a limited improvement in exercise capacity has been demonstrated when COPD patients receive pulmonary or combined heart-lung transplant [7]-[9].

Muscle injury is a concept that refers to a group of morphological abnormalities in muscles that can be associated with either exertion or diseases [10] [11]. These structural signs of muscle injury can be summarized as disruption of membrane structures (sarcolemma, mitochondria, sarcoplasmic reticulum and T-tubules), degeneration of the cytoplasm, and disorganization of the contractile myofibrils (including sarcomere disruptions, Z-band streaming, misalignment of the myofilaments, and desmin loss) [10] [11]. It has been demonstrated that the diaphragm (the main respiratory muscle) shows signs of injury at both the cellular and subcellular level in patients with COPD [12]. Moreover, susceptibility to additional muscle injury after exertion (i.e., inspiratory loading) is up to three times higher in COPD patients as compared with control individuals [12]. The ultimate cause of diaphragm injury in COPD is not clear. Although chronically increased loads may heighten regional stress and strain on the diaphragm [10], other non-mechanical factors with systemic effects (e.g., smoking, inflammatory mediators) could also participate in this injury [13].

Given that cigarette smoke is the main cause of COPD [1], we hypothesized that cigarette smoke could be involved in cellular and molecular disturbances found in skeletal muscles of these patients. We postulated that, if this is the case, other skeletal (non-respiratory) muscles should also demonstrate increased signs of injury in association with smoking. To our knowledge, there are few reports describing the potential role of cigarette smoking on respiratory and peripheral muscle injury. The purpose of this study was, first, to evaluate whether muscle injury associates with some relevant change in the expression of selected transcription factors involved in skeletal muscle regeneration (MyoD and myogenin) and, second, to determine if these factors associate with peripheral muscle injury. Finally, the study aimed at the definition of the time-course of both injury and protein changes, if any, in both muscles. 


\section{Methods}

\subsection{Ethics and Study Design}

The Research Ethics Committee of Hospital São Paulo, Federal University of São Paulo (UNIFESP) approved the experimental protocol and the study was performed according to the Helsinki convention for the use and care of animals.

\subsection{Animal Preparation}

Eighty male Wistar rats, two months old and weighing from 175 to $250 \mathrm{~g}$, were housed in an environment of $20^{\circ} \mathrm{C}-22^{\circ} \mathrm{C}$ at $60 \%-80 \%$ relative humidity with $12 \mathrm{~h}$ light-dark cycle. Rat chow and water were supplied ad libitum. We assigned the animals to either of the two study groups (1:1) defined by exposure to cigarette smoke (exposed groups) or exposure to room air (non-exposed controls). Exposure to cigarette smoke included two different forms: single smoke exposure (i.e., one session of $2 \mathrm{~h}$ inhalation), or multiple inhalations (i.e., five or 30 consecutive days of exposure), in daily sessions of $2 \mathrm{~h}$. Animals submitted to a single smoke exposure were euthanized at $0 \mathrm{~h}, 2 \mathrm{~h}, 4 \mathrm{~h}, 24 \mathrm{~h}$ or $48 \mathrm{~h}$ after completing the exposure. The animals exposed to multiple smoke sessions were euthanized after the last session of cigarette smoke inhalation (i.e., Day $5^{\text {th }}$ and Day $30^{\text {th }}$, respectively). Experimental conditions included four rats in all cases.

\subsection{Exposure to Cigarette Smoke}

A previously validated exposure chamber was used [6]. Briefly, the 28 cubic liter chamber $(30 \mathrm{~cm}$ in diameter and $40 \mathrm{~cm}$ in height) was made of transparent Plexiglas, with eight small individual cylinders $(7 \mathrm{~cm}$ in diameter and $20 \mathrm{~cm}$ in length). An opening connection to the main chamber enabled the animal to be exposed to the interior of the chamber. In the group of exposed animals, the chamber received a constant flow of commercial cigarette smoke (0.8 mg nicotine, $10 \mathrm{mg}$ tar and $10 \mathrm{mg}$ carbon monoxide), which came from an aspiration system developed for this study. Carbon monoxide concentration (CO) was monitored and normalized to 45 - 55 ppm. This system had a Venturi valve with three ports: in the left lateral portion of the valve (driving flow) compressed air was connected with a flow of $50-100 \mathrm{ml} / \mathrm{min}$. In the front port (air suction), a lit commercial cigarette without filter was placed. In the right lateral portion (propulsory portion) a connection was made to a lateral and lower hole in the main chamber to transport the cigarette smoke to the main chamber. The CO concentration was maintained by mixing it with a compressed air flow of five L/min by means of a fan. A CO meter (TOXICBiosystem, Middletown, UK) positioned in the main chamber monitored the CO concentration. The smoke was constantly produced and exited to the outside environment at the top of the main chamber. The control group was submitted to the same procedures, inhaling compressed air without cigarette smoke.

\subsection{Euthanasia of Animals and Muscle Sampling}

The rats were anesthetized with intraperitoneal pentobarbital $(50 \mathrm{mg} / \mathrm{kg}$ ) to induce deep anesthesia and sacrificed by exsanguination through the abdominal aorta. Blood samples for cotinine analyses were collected. The blood was centrifuged and the plasma was stored in a glass tube and kept frozen at $-80^{\circ} \mathrm{C}$ until processing and analysis. Samples of the right vastus lateralis and diaphragm were withdrawn. The time elapsed between the withdrawal and freezing or immersion of the muscle samples in $4 \%$ formaldehyde was $\sim 1$ min. Samples were fixed and embedded in paraffin for light microscopy study, as described below.

\subsection{Serum Cotinine Concentration}

Cotinine was measured in duplicate in each sample using an antibody for radioimmunoassay according to the method described by Langone et al. [17] The level of crossed reactivity for cotinine with other nicotine metabolites was less than $5 \%$. The detected measurement variation of the cotinine curve was $0.2-20 \mathrm{ng} / \mathrm{ml}$, with a variation coefficient of $6 \%$ to $10 \%$.

\subsection{Evaluation of Sarcolemmal Disruptions}

Muscle specimens were first dissected free of visible connective tissue and fat and embedded in paraffin using conventional methods. Ten-micrometer sections were cut, varying the inclination of the holder by 5 degree in- 
crements until the minimum cross-sectional area was obtained, which was defined as truly transverse [14]. For assessment and quantification of muscle injury we chose a method based on light microscopy. Cellular membrane permeability to albumin is a sign of membrane injury [15]-[17]. Each sample was processed for immunohistochemical techniques using a polyclonal rabbit anti-human antibody directed against albumin (Code No. A0001; DakoCytomation, DK-2600 Glostrup, Denmark) as a primary antibody. This immunocomplex was detected using a horseradish peroxidase-labeled goat anti-rabbit secondary antibody (Code No. K4003; EnVision + System-HRP labeled polymer, Dako Co., Carpinteria, CA, USA). The reaction was developed with a chromogen solution with 3.3-diaminobenzidine (Code No. K3468; Liquid DAB + Substrate-Chromogen Solution, Dako Co., Carpinteria, CA, USA). The analysis of intracellular albumin was performed in duplicate (double-blind approach) using a categorical scale (0 - 3) with a light microscope (Olympus, Series AX70TF; Olympus Optical Co., Shinjukuku, Tokyo, Japan) coupled with an image-digitizing camera (View Finder Lite; Version 1.0.143c; Pixera Co., Los Gatos, CA) and a morphometry program (Scion Image, Version Beta 4.0.2; Scion Co., Frederick, MD, USA). Qualification of fiber injury was performed in a four-category finite interval system, the extremes representing either the absence of intracellular albumin (i.e., absence of sarcolemmal injury, Degree 0), or presence of intracellular albumin on the complete cellular area (i.e., Degree 3). The two intermediate categories were determined by Degree 1 injury (i.e., presence of albumin in less than 50\% of the fiber area) and Degree 2 injury (i.e., presence of albumin on more than $50 \%$ of the fiber area, but not in all of it). The mean value of the findings obtained by two observers was used for statistical analysis.

\subsection{Evaluation of Sarcomere Disruptions}

Samples were processed according to standard methods (Tissue Processor E9200, Biorad, Watford, UK) described elsewhere (12). Micrographs of the muscle samples were taken from 16 randomly selected fields at constant calibrated magnifications $(\times 1900)$ using a transmission electron microscope (Philips CM100, Amsterdam, The Netherlands). An accelerating voltage of $60 \mathrm{kV}$ was used. Disrupted sarcomeres were evaluated as a sign of subcellular muscle injury and defined as a zone with distinct distortion of the usual sarcomeric architecture, following six criteria: discontinuity of a group of myofibrils, A- and I-band disruption, Z-band streaming, embedded subcellular components (mitochondria or collagen), preserved adjacent sarcomere, and absence of regional sectioning artifacts (scratches, holes, or chatters). To quantify the subcellular injury, the proportion of disrupted sarcomere (i.e., abnormal area fraction $\left[\mathrm{A}_{\mathrm{Ab}}\right]$ ) was normalized to the micrographed area and expressed as percentage. This analysis of sarcomere disruption was performed in duplicate using a double-blind approach. The mean value obtained by the two observers was used for the statistical analysis.

\subsection{Immunodetection of MyoD, Myogenin and $\alpha$-Tubulin}

Immunoblots were performed as previously described [18]. In brief, frozen muscle samples (5 - $10 \mathrm{mg}$ ) were homogenized (1:10 w/v) in cold $10 \mathrm{mM}$ Tris buffer $\mathrm{pH} 7.5$ containing 1\% sodium duodecyl sulphate (SDS) and a protease inhibitors cocktail (Roche Diagnostics, Mannheim, Germany). Samples were centrifuged at 10,000 rpm for $10 \mathrm{~min}$ at $4^{\circ} \mathrm{C}$. One hundred $\mu \mathrm{l}$ of the resulting supernatant was mixed with an equal volume of loading buffer (125 mM Tris, pH 6.8, 4\% SDS, 20\% glycerol, 10\% 2-mercaptoethanol and 0.005\% bromophenol blue), which was then boiled for $4 \mathrm{~min}$. The rest of the supernatant was kept at $-80^{\circ} \mathrm{C}$ for further analysis. Proteins were determined by DC Protein Assay from BioRad (California, USA). Thirty-one micrograms of protein were loaded in a 10\% polyacrylamide gel and submitted to electrophoresis (SDS-polyacrylamide gel electrophoresis). Proteins were transferred to 0.45 micron nitrocellulose membranes (Amersham) using a BioRad Mini TransBlot Cell, according to the manufacturer's instructions [19]. Membranes were incubated in a phosphate-buffered saline (PBS) containing 10\% non-fat dry milk, 0.5\% bovine serum albumin and 0.2\% Tween 20 (blocking solution) for $2 \mathrm{~h}$ at room temperature with gentle rocking. Then, membranes were first incubated over night at $4{ }^{\circ} \mathrm{C}$ in blocking solution containing the primary and, after washing, secondary antibodies. We used the following antibodies: anti-MyoD at 1:500 dilution (BD Biosciences Pharmigen, USA), anti-myogenin at 1:1000 dilution (BD Biosciences Pharmigen, USA) and anti- $\alpha$-tubulin mouse monoclonal antibody (Sigma Chemical CO. St. Louis, MO. USA) at 1:1000 dilution. The secondary antibody, a horseradish peroxidase-linked donkey anti-mouse IgG for MyoD, myogenin and $\alpha$-tubulin (Amersham International; Buckinghamshire, UK), was incubated at 1:2000 dilution in blocking solution at room temperature for $2 \mathrm{~h}$. Blots were finally developed with the chemiluminescent peroxidase substrate (Sigma Chemical Co. St. Louis, MO. USA) and visualized with the GeneGenius gel 
documentation and analysis system (Syngene, Cambridge, UK). Band intensities (integrated optical density) were determined by densitometric analysis using the GeneTools software (Syngene). Band results were always normalized by the $\alpha$-tubulin content.

\subsection{Statistical Analysis}

The variables are expressed as mean and standard deviation (SD). Kurtosis of each variable was evaluated. Variables with normal distribution were analyzed using parametric tests. Non-normal variables were analyzed with non-parametric tests. Specifically, cotinine concentrations and structural variables were compared between groups using the unpaired Student's t-test and Mann-Whitney U test. Pearson or Spearman coefficient was calculated to evaluate the possibility of association between the variable sarcolemma injury and the serum cotinine. The accepted alpha risk level was 0.05 . The SPSS software version 10.0 was used for all statistical analysis.

\section{Results}

\subsection{Single Exposure to Cigarette Smoke}

Serum cotinine was used as a marker to confirm inhalation of cigarette smoke. Single sessions of smoking associated with a significant increase of serum cotinine from $0.5 \pm 0.3$ to $8.3 \pm 8.3 \mathrm{ng} / \mathrm{ml}(\mathrm{p}<0.0001)$ and carboxihemoglobin concentration (maximum values $4.12 \% \pm 1.5 \%$ ).

\subsection{Cigarette Smoke Induces Damage of the Muscle Membrane}

In order to evaluate disruption of the muscle membrane, we were guided by the detection of intracellular albumin (Figure 1). A mean of $271 \pm 85$ fibers (range, 132 - 513 fibers per sample) were evaluated in each case. In

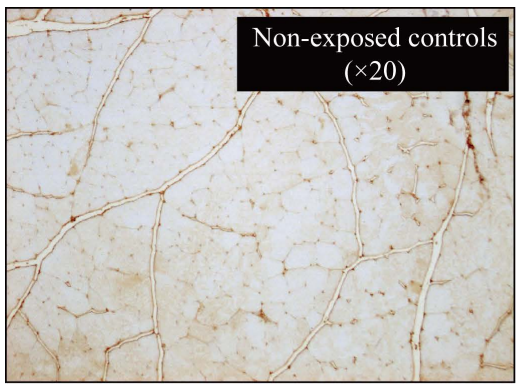

(a)

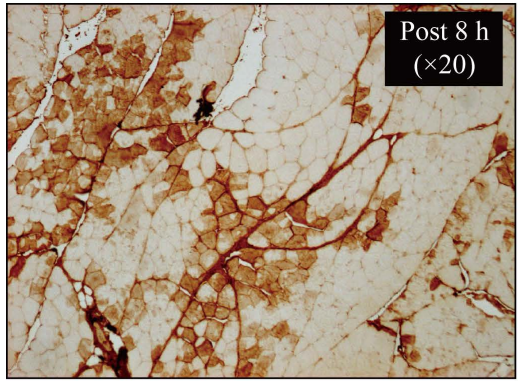

(d)

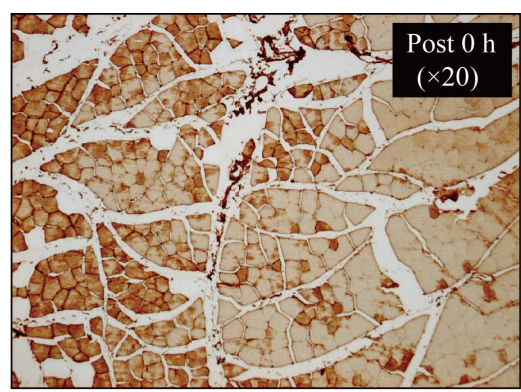

(b)

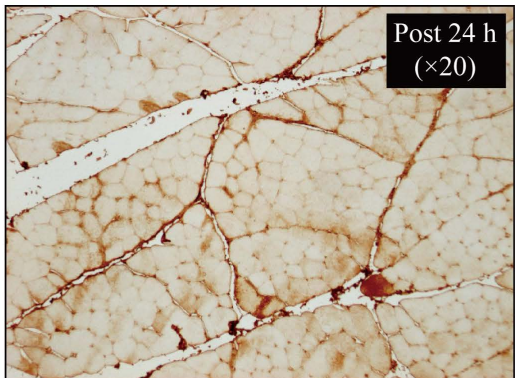

(e)

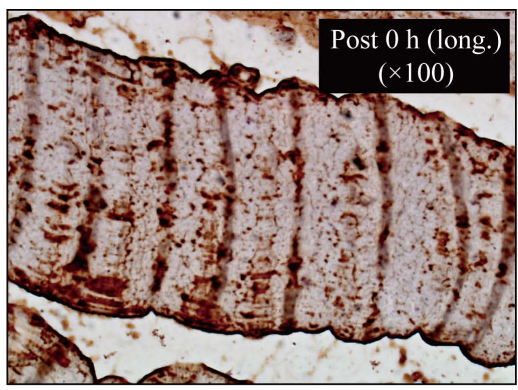

(c)

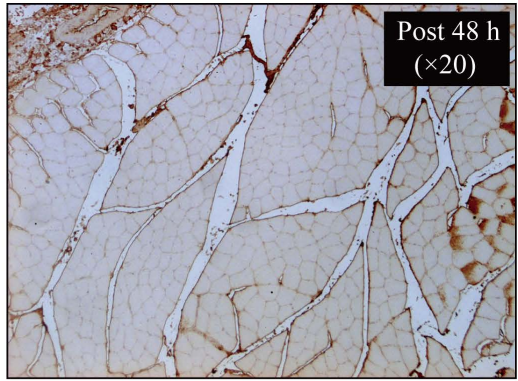

(f)

Figure 1. Exposure to cigarette smoke during a single session associates with sarcolemmal disruptions of the peripheral muscles. Representative micrographs of vastus lateralis fibers structure obtained by using light microscopy for the detection of intracellular albumin using monoclonal antibodies. Cells showing membrane damage (permeability to high molecular weight molecules) appear in red-brown colors. To evaluate the time course of the membrane injury, animal groups were euthanized at $0 \mathrm{~h}, 4 \mathrm{~h}, 24 \mathrm{~h}$ or $48 \mathrm{~h}$ after a single smoking exposure. Signs of sarcolemmal disruptions were present in a few fibers of samples from control animals (a), which suggests that this disruptions represent a physiological (potentially reparative) process. Neverhteless, animals exposed to inhaled cigarette smoke during a single 2 hours session showed a significant increase of sarcolemmal disruptions ((b), (c), (d), (e) and (f)), as an expression of detrimental metabolic mechanisms induced by cigarette smoke (even in absence of exertion). 
the control groups, the proportion of fibers with sarcolemmal damage (i.e., injury) was $5.8 \% \pm 4.3 \%$. Single exposure to cigarette smoke associated with increased percentage of muscle cells with sarcolemmal injury. The mean relative difference (MRD) between exposed animals and controls was wide (Table 1 and Table 2), with the greatest injury at the $0 \mathrm{~h}$ after a single exposure (MRD: 551\%). Consecutive smoking exposure associated with a persistent increase of cells showing membrane damage (128\% at Day 5; 66\% at Day 30).

\subsection{Cigarette Smoke Induces Subcellular Damage}

Transmission electron microscopy was used to evaluate the subcellular contractile structure. Signs of sarcomere disruptions were found in all vastus lateralis samples. Both A- and I-band disruption and Z-band streaming (Figure 2) were observed. In the control groups, the proportion of sarcomere $A_{A b}$ fraction was $3.4 \% \pm 11 \%$. Single exposure to cigarette smoke was not associated with changes in the proportion of disrupted sarcomere. Nevertheless, consecutive exposure to the cigarette smoke was able to induce significant subcellular muscle injury as indicated by the increase of $\mathrm{A}_{\mathrm{Ab}}$ fraction (MRD: 637\% at Day 5; 173\% at Day 30). The range of values of sarcomere disruption was wide $\left(\mathrm{A}_{\mathrm{Ab}}\right.$ range: $8 \%$ - 35\%) significantly higher in the muscle from animals exposed to multiple sessions of cigarette smoke, and with the greatest injury after five sessions of exposure. The consecutive 30 daily exposures associated with a persistent injury at the subcellular level. Figure 3 and Figure 4 show the median value $( \pm 95 \% \mathrm{CI})$ for sarcolemmal and sarcomere disruptions in the different experimental groups.

\subsection{Cigarette Smoke Induces Molecular Response in the Muscles}

Figure 5(a) shows a representative western blot and a bar graph of MyoD expression in the vastus lateralis of both control and exposed groups of animals euthanized at $4 \mathrm{~h}$ or $48 \mathrm{~h}$ intervals following exposure. MyoD expression was rapidly up regulated at $4 \mathrm{~h}$ after exposure (MRD: $937 \% \pm 491 \% \mathrm{p}<0.05$ ) whereas at $48 \mathrm{~h}$ after

Table 1. Degree of sarcolemmal damage associated with smoking exposure.

\begin{tabular}{|c|c|c|c|c|c|c|c|c|}
\hline \multirow{3}{*}{$\begin{array}{l}\text { Sarcolemmal Damage } \\
\text { Time after Exposure }\end{array}$} & & \multicolumn{7}{|c|}{ Exposure to Cigarette Smoke } \\
\hline & & \multicolumn{5}{|c|}{ One Session } & \multicolumn{2}{|c|}{ Multiple Sessions } \\
\hline & & $0 \mathrm{~h}$ & $2 \mathrm{~h}$ & $4 \mathrm{~h}$ & $24 \mathrm{~h}$ & $48 \mathrm{~h}$ & $5 \mathrm{~d}$ & $30 \mathrm{~d}$ \\
\hline \multirow[t]{6}{*}{ Control Animals } & $\mathrm{N}$, & 7 & & & & & 8 & 7 \\
\hline & Mean, \% & 4.3 & & & & & 6.9 & 6.0 \\
\hline & Median, \% & 4.8 & & & & & 7.8 & 5.9 \\
\hline & Minimum, \% & 0.0 & & & & & 0.0 & 0.8 \\
\hline & Maximum, \% & 8.25 & & & & & 11.9 & 11.3 \\
\hline & $\mathrm{SD}, \%$ & 4.1 & & & & & 5.2 & 5.2 \\
\hline \multirow[t]{7}{*}{ Exposed Animals } & $\mathrm{N}$, & 8 & 8 & 7 & 8 & 8 & 14 & 14 \\
\hline & Mean, \% & 28.0 & 23.4 & 16.5 & 12.7 & 13.4 & 15.8 & 10.0 \\
\hline & Median, \% & 24.3 & 18.5 & 12.1 & 13.9 & 9.0 & 10.1 & 5.3 \\
\hline & Minimum, \% & 12.9 & 13.8 & 0.0 & 6.8 & 3.9 & 0.0 & 0.0 \\
\hline & Maximum, \% & 50.7 & 42.8 & 41.7 & 16.2 & 31.5 & 46.0 & 29.3 \\
\hline & $\mathrm{SD}, \%$ & 16.0 & 13.1 & 17.8 & 4.3 & 12.9 & 15.2 & 10.5 \\
\hline & MRD, \% & 551 & 444 & 283 & 195 & 211 & 128 & 66 \\
\hline
\end{tabular}

Legend: Central tendency, dispersion and extreme values of the percentage of cells with signs of sarcolemmal damage (i.e., injury) as assessed by detection of intracellular albumin. Abbreviations: (h): hours; (d): days; (N): number of animals/group; (SD): standard deviation; (MRD): mean relative difference referred to control group. 
Table 2. Degree of sarcomere damage associated with smoking exposure.

\begin{tabular}{|c|c|c|c|c|c|c|c|c|}
\hline \multirow{3}{*}{$\begin{array}{l}\text { Sarcomere Damage } \\
\text { Time after Exposure }\end{array}$} & & \multicolumn{7}{|c|}{ Exposure to Cigarette Smoke } \\
\hline & & \multicolumn{5}{|c|}{ One Session } & \multicolumn{2}{|c|}{ Multiple Sessions } \\
\hline & & $0 \mathrm{~h}$ & $2 \mathrm{~h}$ & $4 \mathrm{~h}$ & $24 \mathrm{~h}$ & $48 \mathrm{~h}$ & $5 d$ & $30 \mathrm{~d}$ \\
\hline \multirow[t]{6}{*}{ Control Animals } & $\mathrm{N}$, & 7 & & & & & 8 & 7 \\
\hline & Mean, \% & 1.3 & & & & & 3.5 & 6.0 \\
\hline & Median, \% & 2.0 & & & & & 2.0 & 5.9 \\
\hline & Minimum, \% & 0.0 & & & & & 1.0 & 0.8 \\
\hline & Maximum, \% & 2.0 & & & & & 9.0 & 11.4 \\
\hline & $\mathrm{SD}, \%$ & 1.2 & & & & & 3.7 & 5.3 \\
\hline \multirow[t]{7}{*}{ Exposed Animals } & $\mathrm{N}$, & 8 & 8 & 7 & 8 & 8 & 14 & 14 \\
\hline & Mean, \% & 3.8 & 5.7 & 4.5 & 5.5 & 4.8 & 25.8 & 16.4 \\
\hline & Median, \% & 2.5 & 5.6 & 3.5 & 5.4 & 3.6 & 27.5 & 16.0 \\
\hline & Minimum, \% & 2.0 & 2.2 & 2.0 & 2.0 & 2.5 & 16.0 & 11.0 \\
\hline & Maximum, \% & 8.0 & 9.5 & 9.0 & 9.0 & 9.5 & 35.0 & 21.0 \\
\hline & $\mathrm{SD}, \%$ & 2.9 & 3.3 & 3.1 & 3.1 & 3.2 & 7.6 & 3.4 \\
\hline & MRD, \% & 192 & 338 & 246 & 323 & 269 & 637 & 173 \\
\hline
\end{tabular}

Legend: Central tendency, dispersion and extreme values of the abnormal area fraction (\%) of disrupted sarcomeres as assessed by electron microscopy following six criteria ${ }^{12}$ : discontinuity of a group of myofibrils, A- and I-band disruption, Z-band streaming, embedded subcellular components (mitochondria or collagen), preserved adjacent sarcomere, and absence of regional sectioning artifacts (scratches, holes, or chatters). To quantify the subcellular injury, both density (i.e., number of areas containing disrupted sarcomere, expressed as n/100 $\mu m^{2}$; and proportion (i.e., abnormal area fraction, expressed as percentage) of disrupted sarcomere were normalized to the micrographed area. Abbreviations: (h): hours; (d): days; (N): number of animals/group; (SD): standard deviation; (MRD): mean relative difference referred to control group.

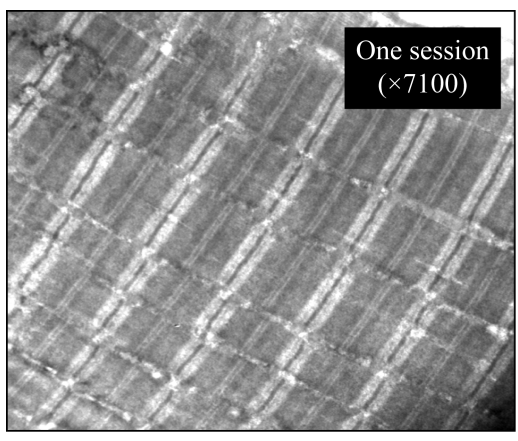

(a)

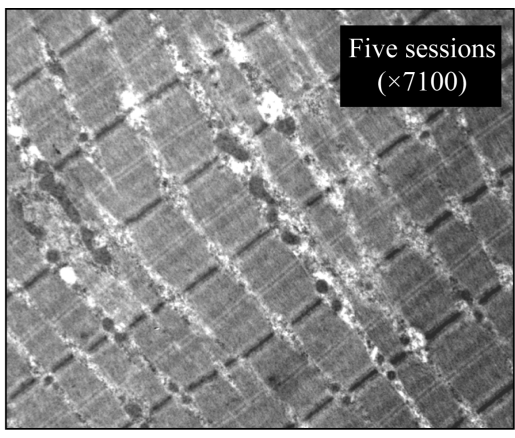

(b)

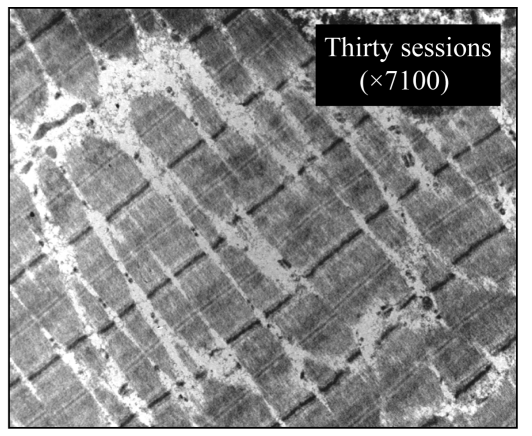

(c)

Figure 2. Peripheral muscles are susceptible to subcellular injury in association with multiple exposures to cigarette smoke. Representative figures of sarcomere disruptions as assessed by transmission electron microscopy $(\times 1900)$. Disrupted sarcomeres were evaluated as a sign of muscle injury and defined as a zone with distinct distortion of the usual sarcomeric architecture, defined by six criteria: discontinuity of a group of myofibrils; A- and I-band disruption, Z-band streaming; embedded subcellular components (mitochondria or collagen); preserved adjacent sarcomere; and absence of regional sectioning artifacts (scratches, holes, or chatters). Sarcomere disruptions were infrequent in muscle samples from control animals or animals exposed to a single session of smoking (a). Nevertheless, sarcomere disruptions were increased in all samples from both animals exposed to five (b) or thirty (c) daily sessions of smoke. The range of values of sarcomere disruption was wide and with the greatest injury after 5 sessions of exposure. 


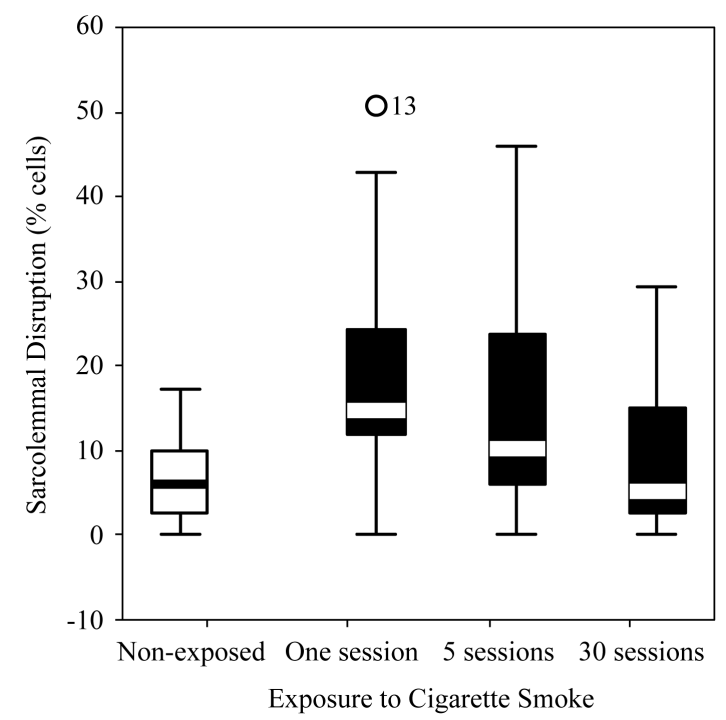

(a)

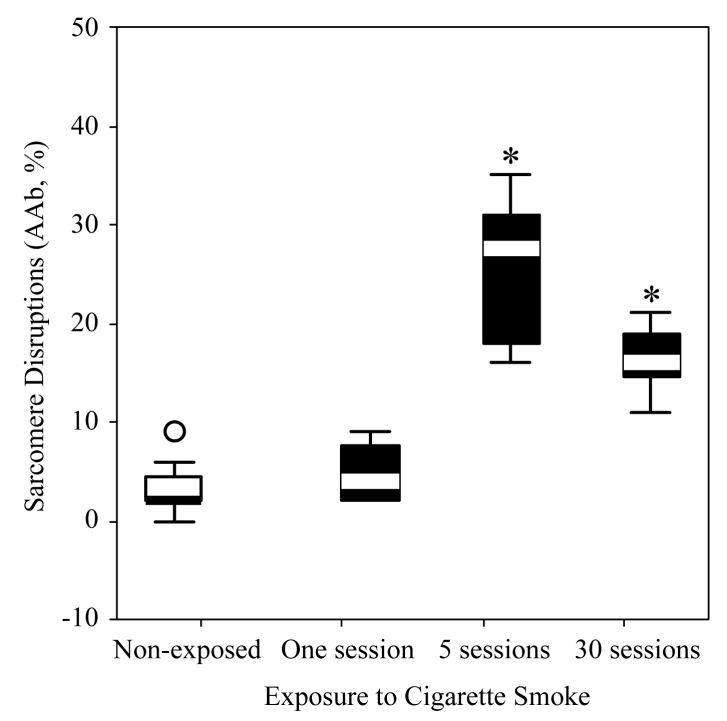

(b)

Figure 3. Sarcolemmal and sarcomeric disruptions show different time course and different magnitudes. Box-plot showing median (horizontals), 95\%CI (box) and extreme values (bars) of both sarcolemmal (a) and sarcomeric (b) disruptions in controls and exposed animals related to cigarette smoke. Sarcolemmal permeability (i.e., membrane damage or injury) was evident early after a single exposure to cigarette smoke. On the other hand, subcellular damage (i.e., sarcomeric disruptions) increased after multiple exposures to cigarette smoke. Both detrimental structural changes show a tendency to decrease in the face of multiple exposures reflecting the induction of potential adaptive mechanism(s) aimed to preserve muscle structure. Abbreviations: $(*): \mathrm{p}<0.01$.

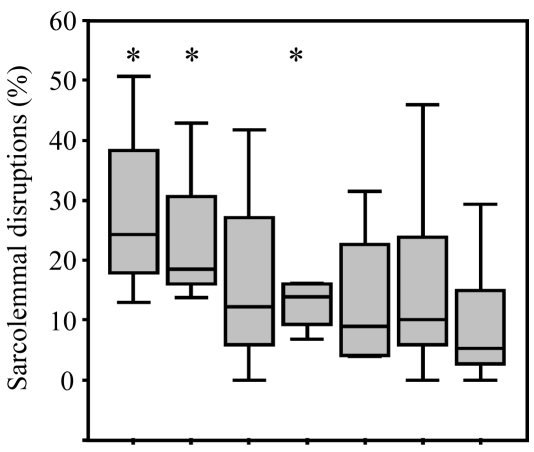

(a)

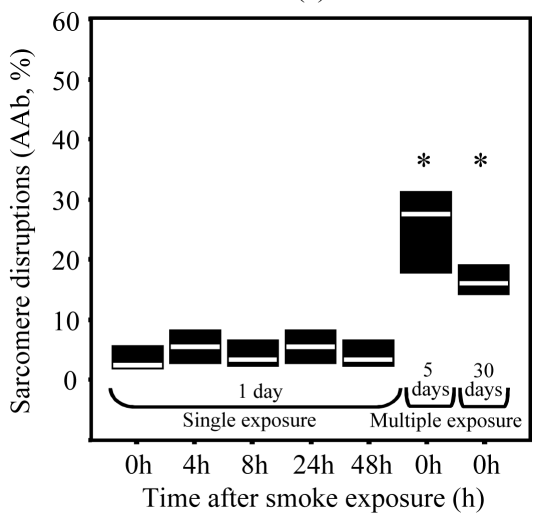

(b)

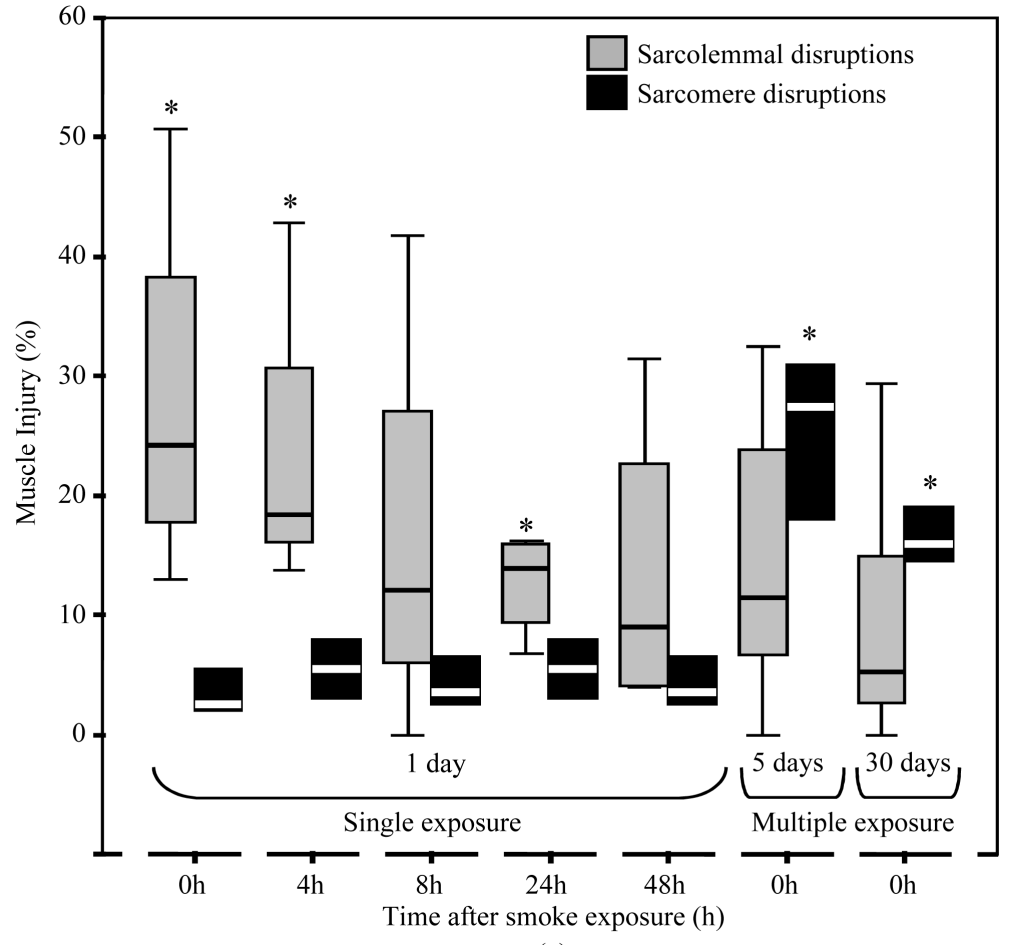

(c)

Figure 4. Early and delayed time course of sarcolemmal and sarcomeric muscle disruptions. Relationships between exposure to cigarette smoke and structural changes at the membrane and subcellular level in the quadriceps muscles of animals. Abbreviations: $(*): \mathrm{p}<0.01$. 

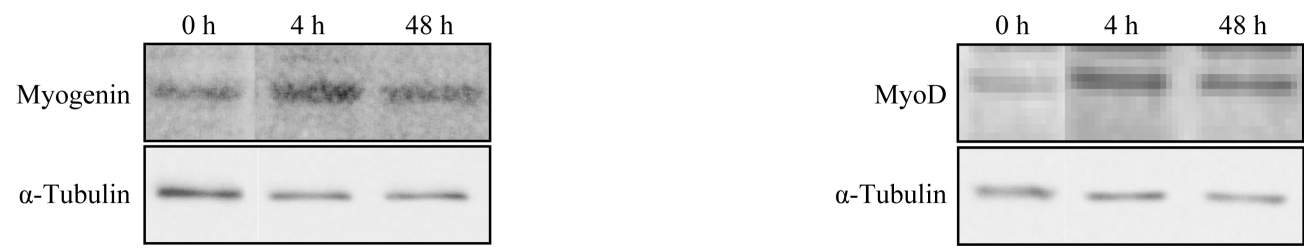

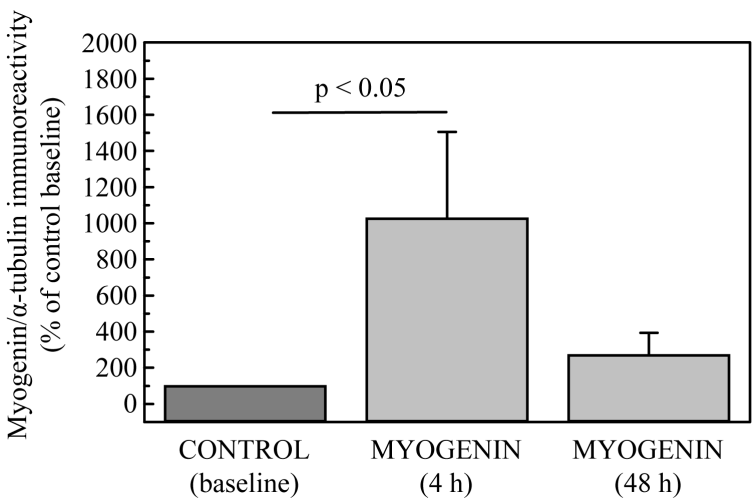

(a)

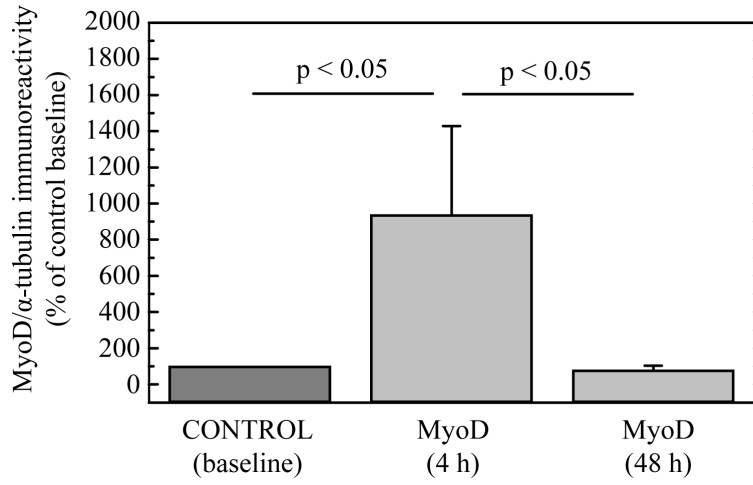

(b)

Figure 5. Effect of cigarette smoke on both myogenin and MyoD protein content at $4 \mathrm{~h}$ and $48 \mathrm{~h}$ after a single $2 \mathrm{~h}$ exposure to cigarette smoke. (a) Representative western blot of MyoD content in vastus lateralis protein extracts. Bar graph shows the mean percentage of control baseline change \pm SEM of myogenin/ $\alpha$-tubulin immunoreactivity in six separate experiments; (b) representative western blot of MyoD content in vastus lateralis protein extracts. Bar graph shows the mean percentage of control baseline change \pm SEM of MyoD/ $\alpha$-tubulin immunoreactivity in six separate experiments.

exposure MyoD expression was similar to normal control values (MRD: $756 \% \pm 25 \%$, $p<0.05$ with regard to increase of MyoD at $4 \mathrm{~h}$ after exposure). Figure 5(b) shows a representative western blot (panel A) and a bar graph (panel B) of myogenin expression in the vastus lateralis of both control and exposed animals euthanized at $4 \mathrm{~h}$ and $48 \mathrm{~h}$ intervals following exposure. Myogenin expression was rapidly up-regulated at $4 \mathrm{~h}$ after exposure $(1029 \% \pm 477 \%, \mathrm{p}<0.05$, with regard to control) whereas at $48 \mathrm{~h}$ after exposure myogenin expression was similar to normal control values.

\section{Discussion}

There are evidences that cellular injury is common in the human diaphragm, that it is more prominent in patients with COPD, and that it is higher after inspiratory loading. Given that cigarette smoking is the main cause of COPD, we hypothesized that gases and particulate matter from cigarette smoke could be involved in the susceptibility to prolonged cellular and molecular disturbances found in these patients [1]. The present study demonstrates that either single or repeated short-term exposure to commercial cigarette smoke induces acute injury on non-exerted peripheral muscles.

Muscle injury is a concept that refers to a group of morphological abnormalities in muscles. Muscle injury is usually restricted to exertion or disease, and the present study very clearly supports that cigarette smoke should also be included in the list of causes of muscle injury. Because all vastus lateralis samples showed unequivocal signs of injury in the non-exposed (control) animals, we postulate that sarcolemmal and sarcomere disruption represents normal (physiological) phenomenon of damage/repair dynamics in muscle fibers. Nevertheless, a particular bimodal time-course was evidenced after the exposure to the cigarette smoke defined by an early development of sarcolemmal disruptions followed by a delayed sarcomere injury. A rapid induction of subrogate markers of skeletal muscle stress and repair processes (MyoD and myogenin protein expression) associated with sarcolemmal and sarcomere damage.

Although the present study was not designed to elucidate the causal factors, the potential mechanisms can be speculated. Acute smoke exposure can result in tissue damage, as suggested by increased products of lipid peroxidation and degradation products of extracellular matrix proteins. On the other hand, acute cigarette smoke has a suppressive effect on the number of eosinophils and on several inflammatory cytokines, possibly due to 
the anti-inflammatory effect of carbon monoxide. Calpain, a cytosolic protease capable of degrading cytoskeletal and myofibrillar proteins, has been involved in muscle injury associated to exertion [13]. Belcastro et al. [20] postulated that increased oxidation may be important in marking proteins for degradation by decreasing their conformational stability [13]. In the present study, animals were not submitted to general or limb exercise. This implies that some systemic factors derived from cigarette smoke induce muscle injury [13] [20]. It is possible that cigarette smoke increases protease activity (e.g., calpain) in the vastus lateralis and might increase oxidation of proteins susceptible to free radical degradation.

Our findings are consistent with previous studies that assessed sarcolemmal injury by detecting intracellular albumin [15]. Transmission electron microscopy is considered a very sensitive method for assessing diverse signs of muscle injury. Compared with the effects of chronic smoke exposure on lung function and airway inflammation, there are few data on the acute effects of smoking. A review of the literature identified 123 studies investigating the acute effects of cigarette smoking on inflammation and oxidative stress in human, animal, and in vitro models [37]. An acute smoking model can supplement other ways of studying the effects of smoking and remains an underinvestigated method for intervention studies in smoking related diseases. Previous studies have demonstrated that when animals perform strenuous exercise, less than $5 \%$ of the fibers in the contracting muscle show overt signs of injury when examined using light microscopy techniques. EM studies can show myofilament disruption in as many as $50 \%$ of the fibers in muscle biopsy specimens. The present study suggests that the severity of muscle injury could be underestimated by using a single morphological technique, because immunohistochemical detection of albumin was sensitive for early $(<24 \mathrm{~h})$ damage whereas electron microscopy was sensitive for subcellular changes which were detected after five or more days of exposure.

\subsection{Molecular Response of Peripheral Muscle after Smoking Induced Injury}

Numerous studies in both animal models and humans have shown that exertion can injure the limb muscles, [10] and this phenomenon may involve several mechanical and metabolic processes [11] [21] [22]. Although exertion-induced injury is associated with impaired muscle function (decreased strength and/or endurance), [10] muscle injury also appears to stimulate complex mechanisms that can induce adaptive repair to stress in skeletal muscles (i.e., training) [23] [24]. Skeletal muscle regeneration after injury is mainly produced by the proliferation and differentiation of adult myoblasts into myotubes, in a process reminiscent of embryonic muscle development [25]. This process is first characterized by the rapid upregulation of MyoD, a primary member of the myogenic regulatory family (MRF), that triggers myoblast proliferation [25]. In our study we clearly show a rapid (4 h after tobacco smoke inhalation) upregulation of $\mathrm{MyoD}$ in vastus lateralis. This up-regulation of MyoD is therefore consistent with the onset of skeletal muscle repair processes (myoblast proliferation) upon injury caused by acute tobacco smoke inhalation. Upregulation of MyoD expression has been detected in several models of muscle regeneration [26]. In this regard, MyoD expression appears to be essential for muscle regenerative capacity, as shown in a MyoD knockout mice model [27]. A second step in skeletal muscle repair and regeneration involves withdrawal of proliferating myoblasts from the cell cycle to become terminally differentiated myotubes. This second step requires inducing the expression of myogenin (a late MRF) [28]. In our study we clearly show a rapid ( $4 \mathrm{~h}$ after tobacco smoke inhalation) up-regulation of myogenin in vastus lateralis. This upregulation of myogenin is also consistent with a progression of skeletal muscle repair processes (satellite cell differentiation into myotubes) upon injury caused by acute tobacco smoke inhalation. In this context, regulation of myogenic pathways for muscle cell growth and differentiation is controlled by NF- $\kappa B$ transcription factor [29]. Therefore, we used western blot analysis to further explore the effect of exposure to tobacco smoke on the

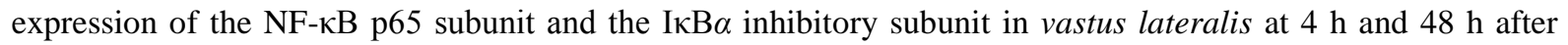
smoking. Our experiments found no differences in the expression of these proteins compared with control non-exposed animals (data not shown). This negative result is consistent with dynamically preserved levels of NF-kB activity, since (as discussed above) tobacco smoke could induce satellite cell (myoblast) proliferation, characterized by both an increased expression of MyoD and NF- $\mathrm{KB}$ activity, on the one hand and on the other hand myotube differentiation characterized by the up-regulation of myogenin and loss of NF-kB activity [29].

\subsection{Relevance of Findings}

The capacity to perform physical exercise is determined for multiple organs and systems [30] [31]. Patients with COPD undergo several degrees of impairment in their capacity to perform exercise and daily physical activities 
[32]-[37]. Impairment of ventilatory function represents the main limiting factor for exercise capacity in most COPD patients. However, extra-pulmonary factors also play a significant role in limiting exercise. Given that cigarette smoking is the main cause of COPD, we hypothesized that gases and particulate matter in smoke could be involved in the prolonged cellular and molecular disturbances found in these patients [1]. The present experimental study confirms that a detrimental effect (as assessed by membrane and subcellular injury) is not only related to multiple but also single, short-term and low-dose inhalation of gases and/or particulate matter from commercial tobacco smoke. Together, these results support the notion that smoking status should be included as a variable in further studies aimed to evaluate the relationships between presence or severity of COPD and skeletal (respiratory and peripheral) muscle function and structure. Nevertheless, the question of how the bimodal time-course and trends observed in membrane and sarcomere injury can explain a persistent muscle dysfunction in patients with COPD even after smoking cessation remains unanswered.

The present study shares the typical limitations of animal studies. Acute smoking models are relatively easy and sensitive method of investigating the specific effects of cigarette smoke. However, the study design does not allow estimating the effects of chronic smoking (longer than one month) on muscle integrity. Finally, it may be argued that nutritional, whole-body metabolism, and functional studies of muscle strength and endurance could have offered comprehensive information regarding the functional translation the findings.

\section{Conclusion}

This study shows that a single exposure for just two hours to commercial cigarette smoke associates with a deleterious effect on the peripheral muscles of mice as assessed by sarcolemmal and sarcomere injury in vastus lateralis muscles. In addition, rapid upregulation of both myogenin and MyoD is detected from $4 \mathrm{~h}$ after tobacco smoke inhalation. These findings may indicate that activation of cellular programs that direct satellite cell proliferation and myotube differentiation (the first and second steps of muscle repair processes) take place in peripheral muscles shortly after tobacco smoke inhalation. Collectively, the results show that peripheral skeletal muscles are susceptible to injury after acute inhalation of tobacco smoke, which is followed by a rapid induction of subrogate markers of skeletal muscle stress and repair processes

\section{Sources of Support}

PLAN DE FORTALECIMIENTO INSTITUCIONAL Ref. 477-2012 y Ref. 734-2013; Proyecto Exención de Impuestos, COLCIENCIAS ref. contrato 656624037813-2013. Red Respira (RTIC C03/11, Fondo de Investigación Sanitaria, Instituto de Salud Carlos III), SEPAR, Ministerio de Educación, Cultura y Deporte de España.

\section{References}

[1] Pauwels, R.A., Buist, A.S., Calverley, P.M., Jenkins, C.R. and Hurd, S.S. (2001) Global Strategy for the Diagnosis, Management, and Prevention of Chronic Obstructive Pulmonary Disease. NHLBI/WHO Global Initiative for Chronic Obstructive Lung Disease (GOLD) Workshop Summary. American Journal of Respiratory and Critical Care Medicine, 163, 1256-1276. http://dx.doi.org/10.1164/ajrccm.163.5.2101039

[2] Agusti, A.G., Noguera, A., Sauleda, J., Sala, E., Pons, J. and Busquets, X. (2003) Systemic Effects of Chronic Obstructive Pulmonary Disease. European Respiratory Journal, 21, 347-360. http://dx.doi.org/10.1183/09031936.03.00405703

[3] Ferrer, M., Alonso, J., Morera, J., Marrades, R.M., Khalaf, A., Aguar, M.C., Plaza, V., Prieto, L. and Anto, J.M. (1997) Chronic Obstructive Pulmonary Disease Stage and Health-Related Quality of Life. The Quality of Life of Chronic Obstructive Pulmonary Disease Study Group. Annals of Internal Medicine, 127, 1072-1079. http://dx.doi.org/10.7326/0003-4819-127-12-199712150-00003

[4] Yohannes, A.M., Roomi, J., Waters, K. and Connolly, M.J. (1998) Quality of Life in Elderly Patients with COPD: Measurement and Predictive Factors. Respiratory Medicine, 92, 1231-1236. http://dx.doi.org/10.1016/S0954-6111(98)90426-7

[5] Decramer, M., Gosselink, R., Troosters, T., Verschueren, M. and Evers, G. (1997) Muscle Weakness Is Related to Utilization of Health Care Resources in COPD Patients. European Respiratory Journal, 10, 417-423. http://dx.doi.org/10.1183/09031936.97.10020417

[6] Engelen, M.P., Schols, A.M., Does, J.D. and Wouters, E.F. (2000) Skeletal Muscle Weakness Is Associated with Wasting of Extremity Fat-Free Mass But Not with Airflow Obstruction in Patients with Chronic Obstructive Pulmo- 
nary Disease. The American Journal of Clinical Nutrition, 71, 733-738.

[7] Lands, L.C., Smountas, A.A., Mesiano, G., Brosseau, L., Shennib, H., Charbonneau, M. and Gauthier, R. (1999) Maximal Exercise Capacity and Peripheral Skeletal Muscle Function Following Lung Transplantation. The Journal of Heart and Lung Transplantation, 18, 113-120. http://dx.doi.org/10.1016/S1053-2498(98)00027-8

[8] Starkey, D.B., Pollock, M.L., Ishida, Y., Welsch, M.A., Brechue, W.F., Graves, J.E. and Feigenbaum, M.S. (1996) Effect of Resistance Training Volume on Strength and Muscle Thickness. Medicine Science in Sports Exercise, 28, 1311-1320. http://dx.doi.org/10.1097/00005768-199610000-00016

[9] Trulock III, E.P. (1998) Lung Transplantation for COPD. Chest, 113, 269S-276S. http://dx.doi.org/10.1378/chest.113.4_Supplement.269S

[10] Friden, J., Sjostrom, M. and Ekblom, B. (1983) Myofibrillar Damage Following Intense Eccentric Exercise in Man. International Journal of Sports Medicine, 4, 170-176. http://dx.doi.org/10.1055/s-2008-1026030

[11] Reid, W.D. and MacGowan, N.A. (1998) Respiratory Muscle Injury in Animal Models and Humans. Molecular and Cellular Biochemistry, 179, 63-80. http://dx.doi.org/10.1023/A:1006803703128

[12] Orozco-Levi, M., Gea, J., Lloreta, J.L., Felez, M., Minguella, J., Serrano, S. and Broquetas, J.M. (1999) Subcellular Adaptation of the Human Diaphragm in Chronic Obstructive Pulmonary Disease. European Respiratory Journal, 13, 371-378. http://dx.doi.org/10.1183/09031936.99.13237199

[13] Jiang, T.X., Reid, W.D., Belcastro, A. and Road, J.D. (1998) Load Dependence of Secondary Diaphragm Inflammation and Injury after Acute Inspiratory Loading. American Journal of Respiratory and Critical Care Medicine, 157, 230236. http://dx.doi.org/10.1183/09031936.99.13237199

[14] Poole, D.C., Lieber, R.L. and Mathieu-Costello, O. (1994) Myosin and Actin Filament Lengths in Diaphragms from Emphysematous Hamsters. Journal of Applied Physiology, 76, 1220-1225.

[15] Hamer, P.W., McGeachie, J.M., Davies, M.J. and Grounds, M.D. (2002) Evans Blue Dye as an in Vivo Marker of Myofibre Damage: Optimising Parameters for Detecting Initial Myofibre Membrane Permeability. Journal of Anatomy, 200, 69-79. http://dx.doi.org/10.1046/j.0021-8782.2001.00008.x

[16] Straub, V., Rafael, J.A., Chamberlain, J.S. and Campbell, K.P. (1997) Animal Models for Muscular Dystrophy Show Different Patterns of Sarcolemmal Disruption. The Journal of Cell Biology, 139, 375-385. http://dx.doi.org/10.1046/j.0021-8782.2001.00008.x

[17] Langone, J.J. and Van Vunakis, H. (1982) Radioimmunoassay of Nicotine, Cotinine, and Gamma-(3-Pyridyl)-Gammaoxo-N-Methylbutyramide. Methods in Enzymology, 84, 628-640. http://dx.doi.org/10.1016/0076-6879(82)84050-0

[18] Agusti, A., Morla, M., Sauleda, J., Saus, C. and Busquets, X. (2004) NF-KappaB Activation and iNOS Upregulation in Skeletal Muscle of Patients with COPD and Low Body Weight. Thorax, 59, 483-487. http://dx.doi.org/10.1136/thx.2003.017640

[19] Tolosa, L., Morla, M., Iglesias, A., Busquets, X., Llado, J. and Olmos, G. (2005) IFN-Gamma Prevents TNF-AlphaInduced Apoptosis in C2C12 Myotubes through Down-Regulation of TNF-R2 and Increased NF-KappaB activity. Cellular Signalling, 17, 1333-1342. http://dx.doi.org/10.1016/j.cellsig.2005.02.001

[20] Belcastro, A.N., Shewchuk, L.D. and Raj, D.A. (1998) Exercise-Induced Muscle Injury: A Calpain Hypothesis. Molecular and Cellular Biochemistry, 179, 135-145. http://dx.doi.org/10.1023/A:1006816123601

[21] Armstrong, R.B. (1990) Initial Events in Exercise-Induced Muscular Injury. Medicine Science in Sports Exercise, 22, 429-435.

[22] MacIntyre, D.L., Reid, W.D. and McKenzie, D.C. (1995) Delayed Muscle Soreness. The Inflammatory Response to Muscle Injury and Its Clinical Implications. Sports Medicine, 20, 24-40. http://dx.doi.org/10.2165/00007256-199520010-00003

[23] McNeil, P.L. and Ito, S. (1990) Molecular Traffic through Plasma Membrane Disruptions of Cells in Vivo. Journal of Cell Science, 96, 549-556.

[24] Petrof, B.J., Shrager, J.B., Stedman, H.H., Kelly, A.M. and Sweeney, H.L. (1993) Dystrophin Protects the Sarcolemma from Stresses Developed during Muscle Contraction. Proceedings of the National Academy of Sciences of the United States of America, 90, 3710-3714. http://dx.doi.org/10.1073/pnas.90.8.3710

[25] Charge, S.B. and Rudnicki, M.A. (2004) Cellular and Molecular Regulation of Muscle Regeneration. Physiological Reviews, 84, 209-238. http://dx.doi.org/10.1152/physrev.00019.2003

[26] Cooper, R.N., Tajbakhsh, S., Mouly, V., Cossu, G., Buckingham, M. and Butler-Browne, G.S. (1999) In Vivo Satellite Cell Activation via Myf5 and MyoD in Regenerating Mouse Skeletal Muscle. Journal of Cell Science, 112, 2895-2901.

[27] Megeney, L.A., Kablar, B., Garrett, K., Anderson, J.E. and Rudnicki, M.A. (1996) MyoD is Required for Myogenic Stem Cell Function in Adult Skeletal Muscle. Genes Development, 10, 1173-1183. http://dx.doi.org/10.1101/gad.10.10.1173 
[28] Smith, C.K., Janney, M.J. and Allen. R.E. (1994) Temporal Expression of Myogenic Regulatory Genes during Activation, Proliferation, and Differentiation of Rat Skeletal Muscle Satellite Cells. Journal of Cellular Physiology, 159, 379-385. http://dx.doi.org/10.1002/jcp.1041590222

[29] Guttridge, D.C., Albanese, C., Reuther, J.Y., Pestell, R.G. and Baldwin Jr., A.S. (1999) NF-kappaB Controls Cell Growth and Differentiation through Transcriptional Regulation of Cyclin D1. Molecular and Cellular Biology, 19, 5785-5799.

[30] Coyle, E.F. (1999) Physiological Determinants of Endurance Exercise Performance. Journal of Science and Medicine in Sport, 2, 181-189. http://dx.doi.org/10.1016/S1440-2440(99)80172-8

[31] Dugan, S.A. and Frontera, W.R. (2000) Muscle Fatigue and Muscle Injury. Physical Medicine Rehabilitation Clinics of North America, 11, 385-403.

[32] Bauerle, O., Chrusch, C.A. and Younes, M. (1998) Mechanisms by Which COPD Affects Exercise Tolerance. American Journal of Respiratory and Critical Care Medicine, 157, 57-68. http://dx.doi.org/10.1164/ajrccm.157.1.9609126

[33] Garrod, R., Bestall, J.C., Paul, E.A., Wedzicha, J.A. and Jones, P.W. (2000) Development and Validation of a Standardized Measure of Activity of Daily Living in Patients with Severe COPD: The London Chest Activity of Daily Living scale (LCADL). Respiratory Medicine, 94, 589-596. http://dx.doi.org/10.1053/rmed.2000.0786

[34] Gosselink, R., Troosters, T. and Decramer, M. (1996) Peripheral Muscle Weakness Contributes to Exercise Limitation in COPD. American Journal of Respiratory and Critical Care Medicine, 153, 976-980. http://dx.doi.org/10.1164/ajrccm.153.3.8630582

[35] Rabinovich, R., Vilaro, J. and Roca, J. (2001) [The Role of Peripheral Muscles on Exercise Tolerance in Patients with COPD]. Archivos de Bronconeumología, 37, 135-141. http://dx.doi.org/10.1016/S0300-2896(01)75035-1

[36] Maltais, F., Jobin, J., Sullivan, M.J., Bernard, S., Whittom, F., Killian, K.J., Desmeules, M., Belanger, M. and LeBlanc, P. (1998) Metabolic and Hemodynamic Responses of Lower Limb during Exercise in Patients with COPD. Journal of Applied Physiology, 84, 1573-1580.

[37] van der Vaart, H., Postma, D.S., Timens, W. and ten Hacken, N.H. (2004) Acute Effects of Cigarette Smoke on Inflammation and Oxidative Stress: A Review. Thorax, 59, 713-721. http://dx.doi.org/10.1136/thx.2003.012468 
Scientific Research Publishing (SCIRP) is one of the largest Open Access journal publishers. It is currently publishing more than 200 open access, online, peer-reviewed journals covering a wide range of academic disciplines. SCIRP serves the worldwide academic communities and contributes to the progress and application of science with its publication.

Other selected journals from SCIRP are listed as below. Submit your manuscript to us via either submit@scirp.org or Online Submission Portal.
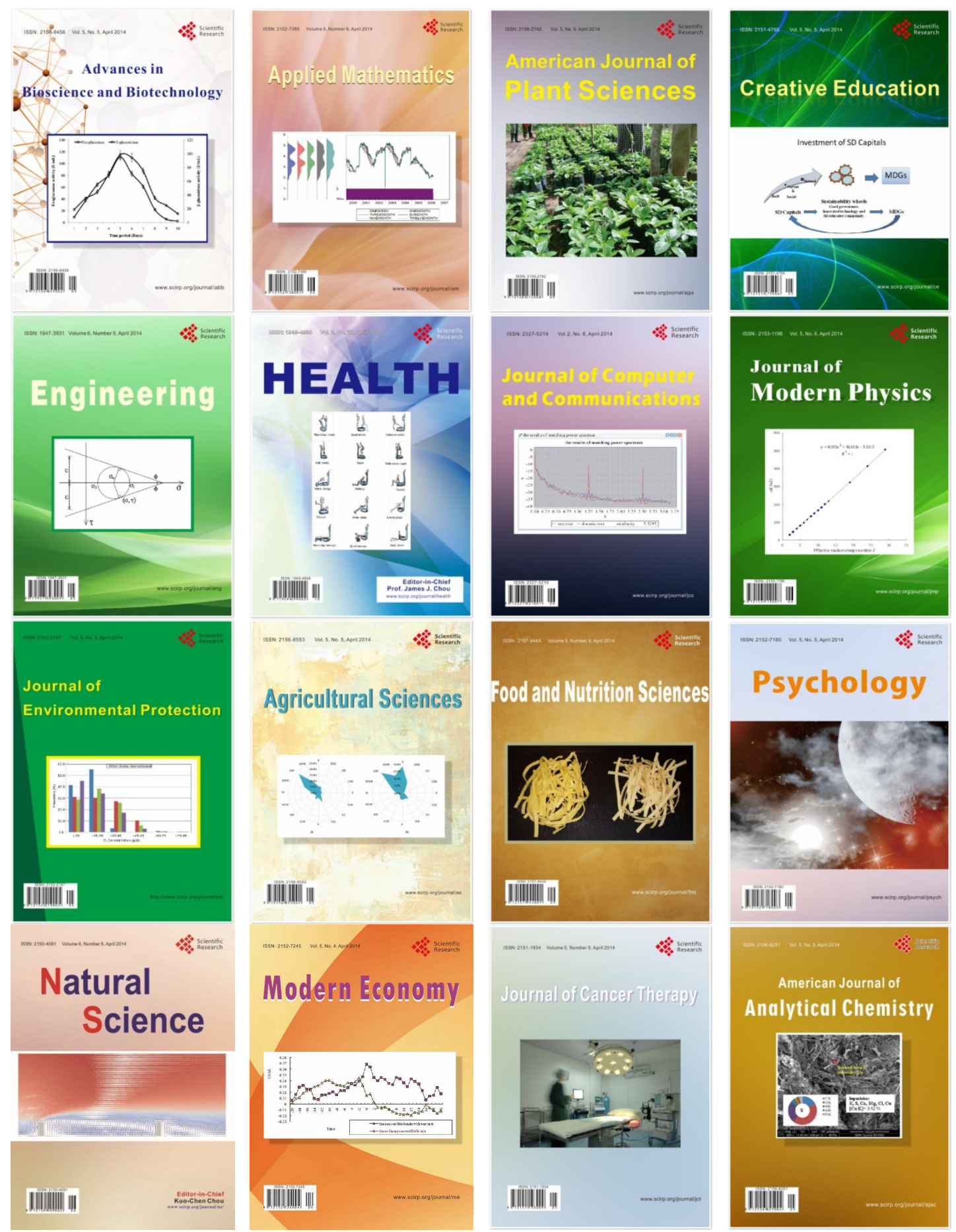